\title{
Effects of Inter-Parental Conflict on Children's Social Well-Being and the Mediation Role of Parenting Behavior
}

\author{
Stephanie Hess ${ }^{1}$ (D)
}

Received: 1 February 2021 / Accepted: 25 November 2021 / Published online: 16 December 2021

(c) The Author(s) 2021

\begin{abstract}
Inter-parental conflicts can have devastating effects on children's well-being and social behavior. This study explores the association between an increased frequency of inter-parental conflict and peer problems and prosocial behavior in children, and whether parents' emotional warmth and negative communication with their children mediates this association. Data for a total of 1,157 children between the ages of 7 and 16 (4,016 observations) was drawn from the eighth to the twelfth waves of the German Family Panel so as to perform fixed-effects regressions and mediation analyses. The analyses reveal that increased inter-parental conflict is strongly related to decreased emotional warmth and increased negative communication in parents, and to increased peer problems and decreased prosocial behavior in children. The results also suggest that the association between inter-parental conflict and children's social well-being is mediated by the parenting behavior of mothers and fathers, indicating that increased inter-parental conflict leads to less warm parenting and more negative communication in parents, which ultimately reduces children's social well-being.
\end{abstract}

Keywords Child social well-being · Inter-parental conflict · Peer problems · Prosocial behavior Parenting behavior

\section{Introduction}

Arguments and conflicts are an inevitable part of family life, and inter-parental conflicts are one of the most prominent, parent-driven factors that negatively influence the home environments of children and adolescents (e.g., Brock \& Kochanska, 2016; Brummert Lennings \& Bussey, 2017; Hosokawa \& Katsura, 2017; Troxel \& Matthews, 2004; Vandewater \& Lansford, 1998). Conflicts between parents have

Stephanie Hess

stephanie.hess@ovgu.de

1 Otto-Von-Guericke University Magdeburg, Zschokkestr. 32, 39106 Magdeburg, Germany 
been identified repeatedly in the literature as crucial risk factors for children's mental health, behavioral and emotional problems, and social behavior (e.g., Auersperg et al., 2019; Davies et al., 2016; McCoy et al., 2009; O'Hara et al., 2019). The literature proposes a multitude of mechanisms to account for this association, which can be grouped into direct and indirect effects. In the former category, inter-parental conflict has been shown to influence children's well-being directly by impairing their feeling of security within the family system, and weakening parent-child attachment (Brock \& Kochanska, 2016; Davies \& Cummings, 1994; Davies et al., 2016). As an indirect effect, inter-parental conflict can severely interfere with parenting behavior, which can, in turn, lead to increased problems for children (e.g., Coln et al., 2013; Hosokawa \& Katsura, 2017; McCoy et al., 2009).

The current study explores whether, and if so to what extent, changes in childperceived inter-parental conflict frequency have an effect on changes in children's social well-being from a longitudinal perspective. It aims to test whether this effect is mediated by the parenting behavior of mothers and fathers, and seeks to answer two research questions: (1) Is an increase in child perceived interparental conflict frequency associated with worse social well-being, that is, with increases in peer problems and decreases in prosocial behavior in children? and (2) Is the association between an increasing frequency of inter-parental conflict and decreasing social well-being in children mediated by changes in the warmth and negative communication of mothers and fathers towards the child?

By examining changes in the frequency of inter-parental conflict rather than levels of inter-parental conflict, this study seeks to build on and expand the current body of literature by acknowledging that conflict frequency is not constant over time. Inter-parental conflict is likely to become more common when disagreements arise, or in difficult phases of family life. Most importantly, children may react differently to increasing inter-parental conflict than to constant levels, as it alters the overall conditions at the family level.

\section{Theoretical Framework and Literature Review}

The theoretical basis for this study was derived from two different theoretical frameworks that explain the transmission effects of parental behavior on children's behavior and well-being. First, the social learning theory (SLT) proposed by Bandura (1969) was used to derive a theoretical explanation for the effect of changes in interparental conflict frequency on changes in children's social well-being. The SLT suggests that individuals acquire certain personality traits and their (social) behavior through frequent interaction with a number of role models - children and adolescents are influenced by their parents' behavior in particular (Bandura, 1969; Bandura \& Walters, 1977). It is thus likely that children who observe frequent inter-parental conflict in their home perceive frequent conflict as an acceptable social behavior and imitate their parents' interaction at school, thus having more frequent conflicts with their peers. Following this argumentation, the first hypothesis tested in this study is. 
H1: Increases in child-perceived inter-parental conflict frequency have a negative impact on children's social well-being. Children who report increasing inter-parental conflict frequency report increases in peer problems and decreases in their prosocial behavior.

Secondly, I derived arguments from the emotional security theory (EST) proposed by Davies and Cummings (1994) to explain the mediating effect of mothers' and fathers' parenting behavior. The EST offers a useful theoretical framework to explain the intersection between parental conflict behavior and children's well-being because it suggests a cascade of negative effects on family members. According to the theory, children generally pursue a goal of feeling safe and secure in their family environment, however, when they are (repeatedly) exposed to inter-parental conflict that is accompanied by negative behavior between parents, such as hostility, violence, and unresolved problems, this goal is at risk. The toxic family environment that evolves from inter-parental conflict thus threatens children's mental health and well-being. The theoretical arguments proposed by the EST can be extended through the spillover hypothesis and the compensation hypothesis (e.g., Engfer, 1988; Krishnakumar \& Buehler, 2000). Both hypotheses refer to the context of parent-child relationships and suggest that the interactions of parents, parental mood, affect, and behavior can directly interfere with child outcomes. The spillover hypothesis proposes that inter-parental conflict causes negative emotions in parents, which in turn increases negative parent-child interactions such as scolding, criticizing, shouting, and arguing. This ultimately leads to adverse child outcomes (Krishnakumar \& Buehler, 2000). The current study thus tests the hypothesis:

$\mathrm{H} 2$ : Increasing frequency of inter-parental conflict has a negative effect on the parenting practices of mothers' and fathers: children who report increases in the frequency of inter-parental conflict report increasing negative communication with their mothers and fathers.

Analogous to the spillover hypothesis, the compensation hypothesis proposes that family members, and parents in particular, seek to compensate for the negative experiences that result from inter-parental conflict. Parents are likely to invest more time, be more attentive and dedicated towards a child in order to balance the negative environment that results from inter-parental conflict (Engfer, 1988; Erel \& Burman, 1995; Katrijn et al., 2017; Kouros et al., 2014). The third hypothesis investigated in this study is thus:

H3: Increasing inter-parental conflict frequency has a positive effect on the warmth of both parents towards the child: children who report increases in inter-parental conflict frequency report increasing warmth from their mothers and fathers.

Lastly, to test the transmission process suggested by the EST, the current study hypothesizes that:

H4: Maternal and paternal parenting behavior mediates the effect of increasing inter-parental conflict on children's social well-being: increasing inter-parental 
conflict frequency is associated with child-perceived worsening of maternal and paternal parenting behavior which ultimately leads to decreasing social well-being in children.

In addition to the aforementioned theoretical arguments, there is broad empirical evidence that the lives, mental health and happiness of parents decisively shape the well-being of children and adolescents. Parental attributes and behavior can determine whether children oppose deleterious habits such as smoking, are mentally healthy and behave in socially acceptable manners (Dickerson, 2021; Flouri et al., 2019; Nikolaou, 2017). A significant amount of research in recent years has focused on the effect of inter-parental conflict on children's internalizing and externalizing problems (e.g., Davies et al., 2016; Koçak et al., 2017; Kouros et al., 2010; Zemp et al., 2014, 2018).

Some studies have linked inter-parental conflict and children's social well-being, that is, to a variety of children's social behaviors in the school environment. Parental conflict, including marital conflict and intimate partner violence between parents, has been found to predict decreased prosocial behavior, poorer social skills, aggressive behavior, impaired self-control, lower cooperation, and loneliness in children (Holmes et al., 2015; Hosokawa \& Katsura, 2017; Koçak et al., 2017; McCoy et al., 2009).

Studies have revealed a number of transmission processes that explain the mechanism behind the effect of inter-parental conflict on children's well-being. The leading transmitter appears to be the parenting behavior of mothers and fathers (e.g., Camisasca et al., 2016; Coln et al., 2013): Warm parenting behavior towards a child, as well as negative parenting practices such as psychological control and negative communication, have repeatedly been identified as the mediating factors at the intersection of inter-parental conflict and children's prosocial behavior, school adjustment, and overall well-being (Coln et al., 2013; Hosokawa \& Katsura, 2017; Koçak et al., 2017; McCoy et al., 2013; Vandewater \& Lansford, 1998).

The current body of literature, however, has left three major research gaps that this study seeks to fill. First, most of the previous literature is strongly characterized by studies based on data from the United States (e.g., Kouros et al., 2010; McCoy et al., 2013; Miga et al., 2012). Only few studies have documented the detrimental effects of family conflict in non-US contexts that range from various mental problems in adolescents in Hong Kong, Turkey and Egypt (Elemary et al., 2016; Koçak et al., 2017; Low, 2021), and lower self-control skills in Japanese children (Hosokawa \& Katsura, 2017) to more internalizing and externalizing problems in children from Australia (Brummert Lennings \& Bussey, 2017) and poorer academic performance in children from the UK (Harold et al., 2007), for example.

The current study is among the first to investigate the association between children's social well-being and inter-parental conflict using data from a European country, in this case Germany. Findings from studies using US American samples might not be applicable to the German context due to the substantial differences in family-related factors that determine child outcomes. First and foremost, there is a vast difference concerning the use of time within the family environment. Schoolaged children in Germany spend significantly less time in school than their US 
counterparts (Autorengruppe Bildungsberichterstattung, 2020; OECD, 2016, 2020), and parents' working hours are lower in Germany than in the United States (OECD, 2014). Consequently, German children are likely to spend more time at home and with their parents, and might therefore be more frequently exposed to inter-parental conflict than their US American counterparts. Secondly, parenting behaviors differ between the countries. German parents tend to be less strict and more relaxed, authoritative and authoritarian parenting is less common, and permissive parenting is more common in German parents compared to US American parents (Doepke \& Zilibotti, 2019). These differences might result in different relationships between inter-parental conflict frequency, parenting behavior and children's social wellbeing. Lastly, there are distinct differences between German and US American perceptions of parenting duties, values and goals. Empirical evidence from the World Values Survey suggests that US Americans are more likely to believe that it is a parent's duty to do the best for their child even at the expense of their own well-being, and that they value qualities like good manners, hard work, tolerance and respect for others, religious faith, unselfishness and obedience in children more than Germans (Halman et al., 2007). Germans on the other hand value independence, and feelings of responsibility as well as determination and perseverance in children, more than US Americans do (Doepke \& Zilibotti, 2019; Halman et al., 2007).

The second research gap I seek to address is the scarcity of longitudinal evidence on the effect of inter-parental conflict on children's social behavior and well-being in non-US settings. Existing studies on the effect of inter-parental conflict on children's social well-being mostly use a cross-sectional design (e.g., Camisasca et al., 2016; Zemp et al., 2014), but cross-sectional studies often suffer from problems inherent in their design, and are prone to bias due to unobserved heterogeneity (e.g., the personality traits of family members), which may affect inter-parental conflict, parenting behavior, and children's social well-being, and might therefore confound these associations. This study uses panel data and fixed-effects regression models to account for the problem of unobserved heterogeneity. Researchers assume that individualand family-level heterogeneity are constant over time (e.g., Boyce, 2010). The use of repeated observations of individuals makes it possible to statistically control for time-invariant characteristics without directly observing them. Indeed, those problems are widely acknowledged, and various researchers have called for longitudinal approaches to analyze the effect of inter-parental conflict on children's social well-being (e.g., Camisasca et al., 2016; Coln et al., 2013; Gryczkowski et al., 2018; Hosokawa \& Katsura, 2017).

The last contribution of this study is the use of child-reported measures. Many earlier investigations relied on parent-reported inter-parental conflict and parent- or teacher-reported child well-being (e.g., Brock \& Kochanska, 2016; Gryczkowski et al., 2018; Harold et al., 2007), however, earlier studies have repeatedly demonstrated that parents' reports of their children's well-being are seldom congruent with children's self-evaluations, and that parent reports are prone to bias or misconceptions (e.g., Koskelainen et al., 2000; Seiffge-Krenke \& Kollmar, 1998; Waters et al., 2003; White-Koning et al., 2007). A parent's perceptions have been shown to be influenced by their own experiences and feelings, which can lead to overly negative parent reports of children's well-being 
and behavior (Seiffge-Krenke \& Kollmar, 1998; White-Koning et al., 2007). Consequently, it is possible that parents' reports are less reliable than children's self-reports, especially when analyzing the intersection between socially adverse behavior, such as increased inter-parental conflict, and children's well-being. Parents' reports concerning inter-parental conflict might also suffer from social desirability: reports from parents might under- or overestimate the magnitude of inter-parental conflict witnessed by the child - in fact, previous studies that relied on parent-reported inter-parental conflict and parent-reported child outcomes suggest that child-reported measures may provide more reliable and less biased insights (e.g., Kouros et al., 2010; Miga et al., 2012; Zemp et al., 2014).

\section{Methods}

\section{Data}

In this study, I analyzed data from the German interdisciplinary Panel Analysis of Intimate Relationships and Family Dynamics (pairfam). This project is funded by the German Research Foundation (DFG). Pairfam has a multi-cohort (1971-73, 1981-1983, and 1991-93), multi-actor design that enables research on intergenerational transmission processes as well as intergenerational relationships (Huinink et al., 2011). Pairfam initially collected a representative sample of about 12,000 main respondents - known as anchor persons - from the three birth cohorts, and further included data provided by the main respondent's current partner and minor children living in a pairfam household from Wave 2 onward. All children between the ages of 7 and 16 years who reside in a household that was sampled for the pairfam survey are invited to participate in the pairfam study after the anchor person (mother or father) has given their consent for the child's participation. Children voluntarily complete a 15-min Computer Assisted Paper Interview and a self-administered Computer Assisted Self Interview section that includes sensitive questions such as those regarding interparental conflict (Brüderl et al., 2017). For completing the interview children are incentivized with a small gift worth $€ 5$ (Huinink et al., 2011). The adult questionnaires focus on family topics, such as partnership quality and conflict behavior, and the child questionnaires focus on a variety of sociological phenomena that are relevant to children's lives, such as their well-being, family and school life, the parenting of their mother and father, and social relationships (Huinink et al., 2011).

Overall, the quality of the longitudinal child data provided by pairfam is high: the coverage rate is between $70 \%$ (Wave 12) and $90 \%$ (Wave 8 ) and the conditional response rates range from $95 \%$ (Waves $8,10,11$ ) to $96 \%$ (Waves 9, 12) which means that the attrition rate among the child questionnaires is low, with only about $5 \%$ of the children not participating in the questionnaire although their parents had given their consent each year (Brüderl et al., 2017). 


\section{Participants}

The sample in this study consisted of 1,157 children $(4,016$ observations) who participated in the survey at least twice within the observation period from Wave 8 in 2015/2016 to Wave 12 in 2019/2020. Table 1 shows the sample characteristics for the longitudinal sample, as well as information for each cross-sectional wave. Overall, 281 children completed the questionnaire twice within the observation period, 308 children completed the questionnaire three times, 310 children participated in four waves, and 258 children participated in all five waves. The longitudinal sample consisted of $52 \%$ boys and $48 \%$ girls. The participants were aged 7 to 16 with a mean age of 11.5 years. Mothers' ages ranged from 26 to 54 years (mean: 41.2 years), and fathers' ages ranged from 25 to 70 years (mean: 44.0 years).

Because the study focuses on changes in inter-parental conflict frequency, the analysis was restricted to children in two-parent families with married parents. On average, the parents were married for 13.7 years. Eleven percent of the children were only children, $52 \%$ of the children had one sibling, and $37 \%$ had two or more siblings in the household. The parents included in the sample are relatively highly educated. Based on the International Standard Classification of Education (ISCED), $40 \%$ of mothers and $49 \%$ of fathers were highly educated, $55 \%$ of mothers and $46 \%$ of fathers had an intermediate educational level, and $5 \%$ of mothers and fathers had a lower educational level. The majority of mothers were employed (part-time: 59\%, full-time: $22 \%$ and $6 \%$ worked more than $44 \mathrm{~h}$ per week). Only $14 \%$ of mothers were not employed. Nearly half the fathers were working more than full-time, thus putting in overtime (> $44 \mathrm{~h}$ weekly, $47 \%$ ), and $48 \%$ were employed full-time. Only 5\% of the fathers were employed part-time and $0.3 \%$ were not employed. This distribution of employed work in German parents is well in line with the male-dominated dual-earner model (mother employed part-time, father employed full-time), which is prevalent in Germany (Keller \& Kahle, 2018).

\section{Measures}

Children's Social Well-Being In this study, the social well-being of children and adolescents was captured by two dimensions of the Strength and Difficulties Questionnaire (SDQ) developed by Goodman (1997). Overall, the SDQ covers five different domains of child well-being and development: behavioral problems, emotional problems, hyperactivity, peer problems, and prosocial behavior. Each domain is captured through five items. Both children and adolescents are asked to answer the same set of questions on a three-point scale ranging from 0 "not true" to 2 "certainly true", independent of their age. The pairfam data includes the German version of the SDQ. The German SDQ questionnaire has been evaluated and validated multiple times since its initial translation in 1997 (Klasen et al., 2000). There is a version of the questionnaire that is suitable for children because the wording of each item is adjusted specifically to children's needs to ensure proper understanding, and thus to provide measures of the psychological attributes that can be utilized for scientific 


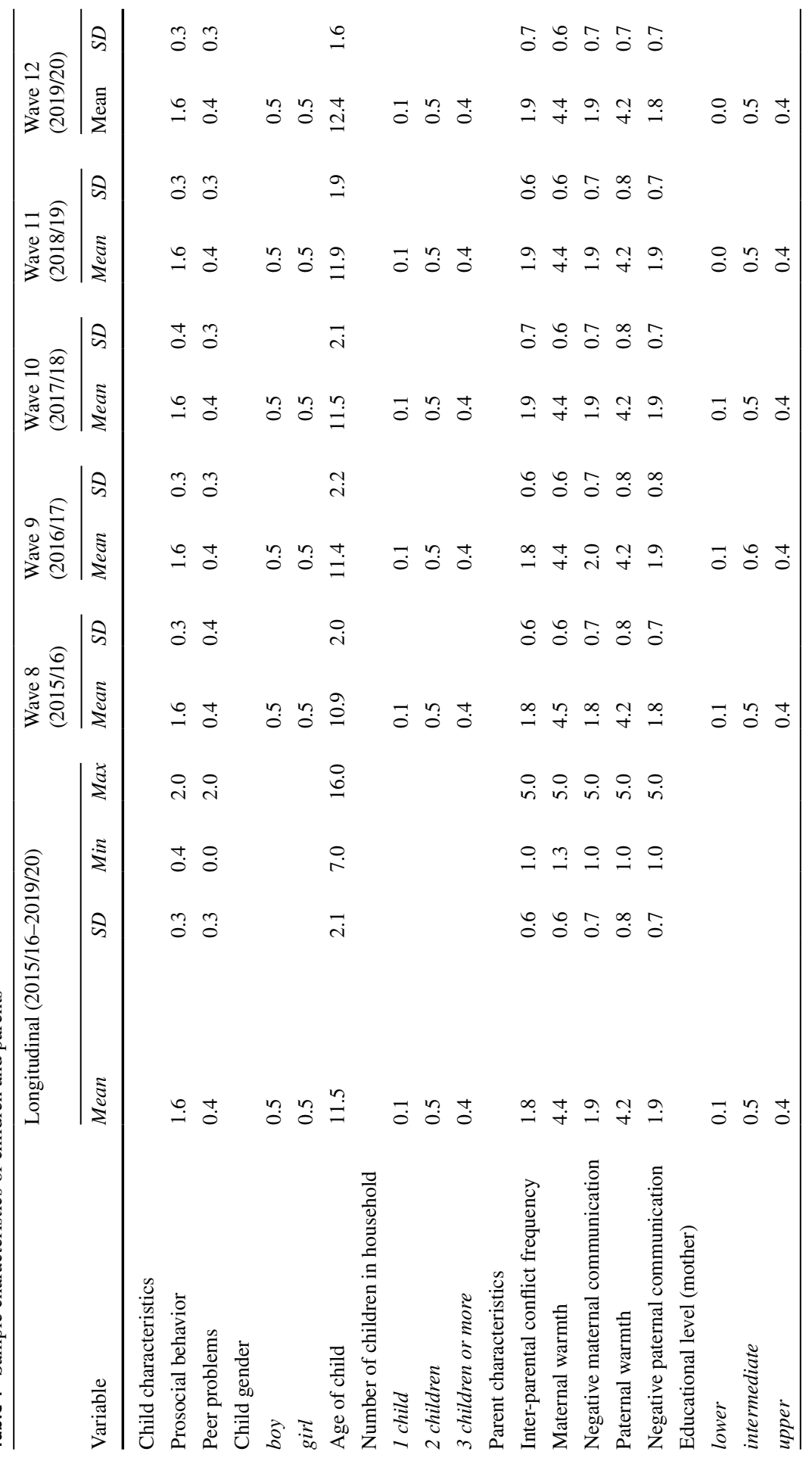




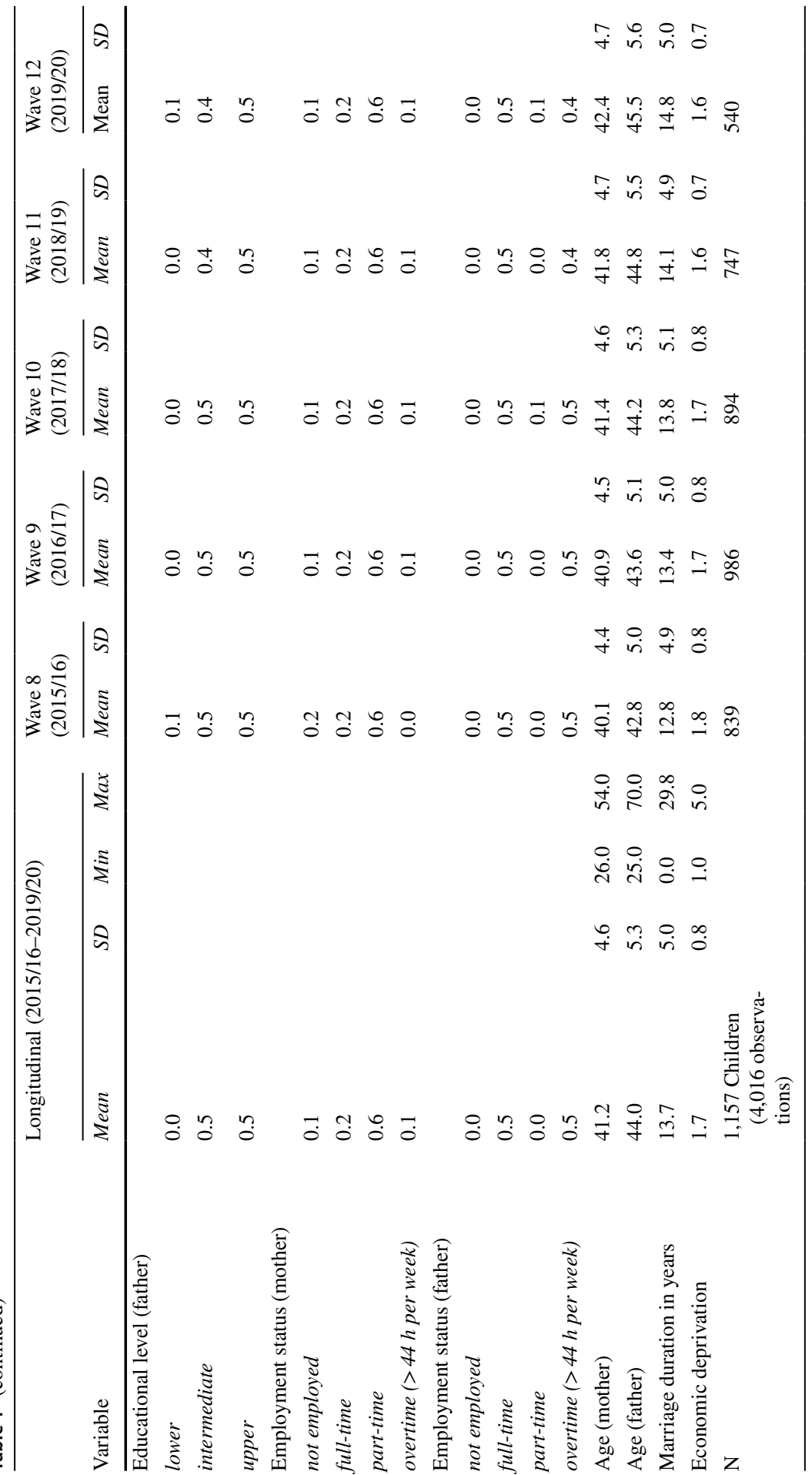


purposes (Youth in Mind, 2012). Because this study focuses on children's social well-being, I used the SDQ domains prosocial behavior and peer problems. The prosocial behavior scale $(\alpha=0.70)$ consists of the items "I am kind to younger children", "I usually share with others (for example, candy, games, markers)", "I try to be nice to other people. I care about their feelings", "I am helpful if someone is hurt, upset or feeling ill", and "I often offer to help others (parents, teachers, children)". The measure used in the analyses to capture prosocial behavior is a sum score for each child in each year which was divided by the number of items answered by the child. The scale thus displays the row mean of prosocial behavior, and higher scores indicate higher levels of prosocial behavior in each child. The prosocial behavior scale ranges from a minimum of 0.4 to a maximum of 2.0, with a mean of 1.6 (see Table 1, longitudinal sample).

The second measure of children's social well-being captures children's peer problems $(\alpha=0.56)$. The children and adolescents were asked to rate the statements: "I would rather be alone than with others", "I have one good friend or more", "Other people at my age generally like me", "I get along better with adults than with other people my age", and "Other children or young people pick on me or bully me" on the scale described above. Positive statements were reversed before constructing a row mean score. Again, higher scores imply a higher level of peer problems. Overall, this scale ranges from a minimum of 0.0 to a maximum of 2.0 (mean: 0.38 , see Table 1, longitudinal sample).

Parental Conflict Behavior This study uses the well-established Children's Perception of Inter-parental Conflict Scale developed by Grych et al. (1992) to assess interparental conflict behavior. The items include objective features of inter-parental conflict as well as appraisal factors. The German version that was used in this study has been translated and shortened, and shows good reliability and validity for the German context (Gödde \& Walper, 2001). The original measure consists of three different dimensions measuring persisting conflict, the child as the subject of the conflict, and the child as mediator. Pairfam only provides items that measure the first dimension.

Child and adolescent perceptions of inter-parental conflict frequency $(\alpha=0.75)$ were assessed through the items "How often do the following things happen between your mother and your father?": "They argue", "They often nag and complain about each other", and "They are mean to each other" on a five-point scale from 1 "never" to 5 "very often". Higher values on the inter-parental conflict frequency scale thus indicate more frequent conflict between mothers and fathers from the child's perspective. The children's assessments of parental conflict frequency range from a minimum of 1.0 to a maximum of 5.0 with a mean of 1.8 (see Table 1, longitudinal sample).

Maternal and Paternal Parenting Behavior This study covers two different parenting behaviors in mothers and fathers: emotional warmth and negative communication. 
First, emotional warmth $(\alpha=0.78)$ involves three items that capture the degree of affirmative attention and care (Jaursch, 2003). The children and adolescents were asked to rate statements on a five-point scale ranging from 1 "never" to 5 "very often". The items that capture maternal and paternal emotional warmth are phrased as follows: "How often does your mother/father show you that they like you?", "How often does your mother/father try to cheer you up when you are sad?", and "How often does your mother/father praise you?". The warmth of mothers and fathers is assessed separately by the children. I constructed a row mean score for the measure and higher scores on the scale translate into a higher prevalence of maternal and paternal warmth. In this sample, the children's evaluations of their mother's emotional warmth range from a minimum of 1.33 to a maximum of 5.0 (mean: 4.4, see Table 1 longitudinal sample) and their fathers' warmth ranges from a minimum of 1.00 to a maximum of 5.00 (mean: 4.2, see Table 1 longitudinal sample). On average children thus perceive their mothers as a little warmer than their fathers.

The items that measure negative communication $(\alpha=0.64)$ are based on an instrument proposed by Schwarz, Walper, Gödde, and Jurasic (1997). It uses three items that specify the degree of a mother's and father's negative verbal parenting towards the child. The children rate the items "How often does your mother/father criticize you?", "How often does your mother/father yell at you because you did something wrong?", and "How often does your mother/father scold you because they are angry at you?" on a five-point scale from 1 "never" to 5 "very often". Again, the negative communication behavior of mothers and fathers was assessed separately. The measure used for the analyses is the row mean of all items answered by the children. Consequently, higher scores on the negative communication scale indicate higher levels of negative communication. The children evaluated negative maternal and paternal communication from a minimum of 1.0 to a maximum of 5.0 (mean mothers: 1.9, mean fathers: 1.9 , see Table 1 longitudinal sample).

Covariates All models control for a variety of child-specific and household-specific socio-demographic variables including child's, mother's and father's age in years; marriage duration in years; number of children living in the household; both parents' educational levels; and the occupational status of both parents, based on their working hours. All models control for the children's perception of economic deprivation in the household on a scale from 0 "not deprived" to 5 "very deprived" (mean in longitudinal sample: 1.7).

\section{Analytical Strategy}

I use the regression-based mediation approach as suggested by Hayes (2013) to analyze whether increasing inter-parental conflict frequency affects children's prosocial behavior and peer problems through maternal warmth and negative communication. This approach makes it possible to identify mediation effects in the triad of inter-parental conflict behavior, maternal, and paternal parenting behavior respectively, and children's social well-being, because it allows a distinction to be made 
between a direct effect of parental conflict frequency on children's social well-being and indirect effects transmitted through maternal and paternal parenting behavior. I utilize fixed-effects (FE) linear regressions with cluster-robust standard errors at the household level to correct for possible heteroskedasticity and the serial correlation of errors within the family. FE models rely solely on within-subject information to estimate the regression parameters (Allison, 2009; Firebaugh et al., 2013) and consequently depend only on intra-individual variation: changes in inter-parental conflict frequency, changes in parenting behavior, and changes in children's social wellbeing. This regression method eliminates unobserved time-invariant heterogeneity such as children's and parents' personality traits. FE models thus eliminate bias due to time-constant unobservables if the unobserved characteristics are indeed timeinvariant. The approach of modeling changes in inter-parental conflict frequency and child social well-being, rather than modeling the level of conflict, also reduces bias due to persistent reporting errors resulting, for instance, from the tendency of individuals to consistently over- or underreport their subjective well-being in different domains. Overall, these properties make FE regressions particularly suitable for examining the intersection of inter-parental conflict frequency, parenting behavior, and children's social well-being.

I conduct the analyses in three steps, each including separate estimates for children's prosocial behavior and children's peer problems. First, I investigate the association between increasing frequency of inter-parental conflict and the parenting behavior of mothers and fathers (negative communication and warmth). Second, I investigate the effect of increasing inter-parental conflict frequency on children's social well-being. In the third and final step, I estimate the direct and indirect effects based on FE regressions with and without controlling for maternal and paternal parenting behavior. This makes it possible to explore the extent to which the effect of changes in the frequency of inter-parental conflict on changes in children's social well-being is transmitted by changes in maternal and paternal warmth and changes in negative maternal and paternal communication. This study uses the Monte Carlo method to assess mediation to determine the confidence intervals for the indirect effects, that is, the effect of inter-parental behavior that is transmitted through parenting behavior. This method treats the parameter estimates from Steps 1 and 2 as parameters, and uses them and their associated asymptotic variances and covariances to simulate random draws from the joint distribution of the indirect paths to construct confidence intervals through re-sampling, thus testing for chance effects (Preacher \& Hayes, 2008; Preacher \& Selig, 2012; Selig \& Preacher, 2008).

Missing values were handled by listwise deletion. Overall, a total of 344 (7.8\%) observations were excluded from the analyses due to missing values on any of the variables included in the models. Most missing values occurred in the inter-parental conflict measure (241 observations) that was captured in CASI mode. Because this represents roughly $70 \%$ of all missing values on a very central variable of this analysis, I conducted a missing value diagnosis. According to Little's Missing Completely At Random (MCAR) Test, the missing values in the sample are not completely random, however, I did not find covariate-dependent missingness for children's age and gender, or children's peer problems or prosocial behavior according to the test's extension for testing the covariate-dependent missingness (CDM: see, 
Li, 2013). Moreover, separate correlation analyses for each variable with missing values indicate that missing values are at random (MAR) - no systematically missing value patterns with regard to children's gender or age, mothers' and fathers' educational level, employment status, marriage duration or the economic deprivation of the household have emerged. Because there were no missing values patterns, all analyses were conducted using a full-information sample.

\section{Results}

\section{Inter-Parental Conflict and Parenting Behavior}

Following the analytical strategy, the models in Table 2 show the results for the effect of changes in inter-parental conflict frequency as perceived by the child, on changes in the warmth of mothers and fathers (Models 1a and 1b) and the negative communication of mothers and fathers (Models $2 \mathrm{a}$ and $2 \mathrm{~b}$ ). The results showed a significant relationship between increased inter-parental conflict and both parenting behaviors in mothers and fathers: child-reported maternal warmth $(b=-0.122$, $p<0.001)$ and child-reported paternal warmth $(b=-0.235, p<0.001)$ were negatively associated with increases in inter-parental conflict frequency. The effect size for fathers was substantially higher, indicating that children perceive a stronger change in paternal warmth compared to maternal warmth. Secondly, both negative maternal communication $(b=0.323, p<0.001)$ and negative paternal communication $(b=0.332, p<0.001)$ were positively associated with increases in inter-parental conflict frequency. Increases in inter-parental conflict were thus associated with decreases in the warmth of both parents, and with increases in negative communication from both parents from the child's perspective. These results are well in line with $\mathrm{H} 2$ : Children who report increases in inter-parental conflict frequency do indeed report increasingly negative communication with their mothers and fathers. The analyses did not reveal evidence for H3, however. Contrary to the theoretical argument proposed by the compensatory hypothesis, children who report increases in inter-parental conflict frequency do not report increasing warmth from their mothers and fathers - no compensatory effect was found.

\section{Inter-Parental Conflict and Children's Social Well-Being}

Table 3 displays the effects of increasing inter-parental conflict frequency on changes in children's social well-being. Models $3 \mathrm{a}$ and $4 \mathrm{a}$ show the effect of changes in the frequency of inter-parental conflict on changes in children's social prosocial behavior and children's peer problems without controlling for the parenting behavior of mothers or fathers. The indicators of inter-parental conflict frequency showed a negative association with children's prosocial behavior $(b=-0.052, p<0.001)$, and a positive association with children's peer problems $(b=0.070, p<0.001)$, thus indicating statistically significant decreases in prosocial behavior and increases in peer problems when there was an increase in inter-parental conflict frequency. The results 
Table 2 Predictors of mothers' parenting behavior (fixed-effects regression, $N=4,016$ observations)

\begin{tabular}{|c|c|c|c|c|c|c|c|c|}
\hline \multirow[b]{4}{*}{ Variable } & \multicolumn{4}{|l|}{ Warmth } & \multicolumn{4}{|c|}{ Negative communication } \\
\hline & \multirow{2}{*}{\multicolumn{2}{|c|}{$\frac{\text { Mothers }}{\text { Model 1a }}$}} & \multirow{2}{*}{\multicolumn{2}{|c|}{$\frac{\text { Fathers }}{\text { Model 1b }}$}} & \multirow{2}{*}{\multicolumn{2}{|c|}{$\begin{array}{l}\text { Mothers } \\
\text { Model 2a }\end{array}$}} & \multirow{2}{*}{\multicolumn{2}{|c|}{$\begin{array}{l}\text { Fathers } \\
\text { Model 2b }\end{array}$}} \\
\hline & & & & & & & & \\
\hline & $b$ & $S E$ & $b$ & $S E$ & $b$ & $S E$ & $\bar{b}$ & $S E$ \\
\hline $\begin{array}{l}\text { Inter-parental conflict fre- } \\
\text { quency }\end{array}$ & $-0.122^{* * *}$ & 0.023 & $-0.235^{* * *}$ & 0.026 & $0.323^{* * *}$ & 0.027 & $0.332^{* * *}$ & 0.031 \\
\hline Age of child ${ }^{a}$ & -0.064 & 0.036 & 0.002 & 0.046 & 0.011 & 0.05 & -0.038 & 0.045 \\
\hline \multicolumn{9}{|c|}{ Number of children in household ${ }^{b}$} \\
\hline 2 children & -0.073 & 0.078 & -0.056 & 0.09 & 0.108 & 0.088 & 0.054 & 0.102 \\
\hline 3 children or more & -0.089 & 0.093 & -0.072 & 0.109 & 0.201 & 0.111 & 0.117 & 0.118 \\
\hline \multicolumn{9}{|l|}{ Educational level (mother) ${ }^{c}$} \\
\hline lower & -0.021 & 0.13 & $0.418^{* * *}$ & 0.108 & 0.032 & 0.222 & 0.05 & 0.169 \\
\hline upper & -0.106 & 0.163 & 0.187 & 0.11 & -0.13 & 0.175 & -0.142 & 0.138 \\
\hline \multicolumn{9}{|l|}{ Educational level (father) ${ }^{d}$} \\
\hline lower & $0.243^{* * *}$ & 0.032 & $0.764^{* * *}$ & 0.039 & $-0.102^{* *}$ & 0.038 & $-0.135^{* *}$ & 0.047 \\
\hline upper & 0.059 & 0.23 & -0.091 & 0.173 & 0.09 & 0.16 & $-0.182^{* *}$ & 0.07 \\
\hline \multicolumn{9}{|l|}{ Employment status (mother) ${ }^{\mathrm{e}}$} \\
\hline not employed & -0.03 & 0.044 & -0.035 & 0.057 & 0.029 & 0.054 & 0.039 & 0.052 \\
\hline part-time & 0.024 & 0.033 & 0.048 & 0.039 & 0.03 & 0.046 & -0.016 & 0.04 \\
\hline overtime (> 44 h per week) & $-0.124^{* *}$ & 0.043 & -0.043 & 0.061 & 0.114 & 0.059 & 0.043 & 0.055 \\
\hline \multicolumn{9}{|l|}{ Employment status (father) ${ }^{\mathrm{f}}$} \\
\hline not employed & $0.142^{*}$ & 0.063 & -0.089 & 0.199 & -0.2 & 0.286 & 0.034 & 0.256 \\
\hline part-time & 0.047 & 0.055 & 0.073 & 0.065 & -0.127 & 0.088 & 0.044 & 0.089 \\
\hline overtime (>44 h per week) & -0.037 & 0.023 & -0.025 & 0.03 & 0.04 & 0.032 & -0.048 & 0.033 \\
\hline Age (mother) ${ }^{g}$ & -0.056 & 0.04 & -0.014 & 0.043 & 0.007 & 0.05 & -0.017 & 0.057 \\
\hline Age (father) ${ }^{h}$ & 0.013 & 0.053 & 0.017 & 0.048 & -0.063 & 0.051 & -0.037 & 0.063 \\
\hline Marriage duration $^{i}$ & 0.058 & 0.082 & -0.065 & 0.082 & 0.032 & 0.09 & 0.072 & 0.11 \\
\hline Economic deprivation & $-0.076^{* * *}$ & 0.016 & $-0.050^{*}$ & 0.02 & $0.067^{* *}$ & 0.022 & $0.056^{*}$ & 0.022 \\
\hline $\mathrm{R}^{2}$ & 0.062 & 0.083 & 0.069 & 0.068 & & & & \\
\hline
\end{tabular}

${ }^{*} p<0.05,{ }^{* *} p<0.01,{ }^{* * *} p<0.001$; Standard Errors clustered on household level

${ }^{\mathrm{a}}$ In years. ${ }^{\mathrm{b}}$ Ref.: 1 child. ${ }^{\mathrm{c}}$ Ref.: Intermediate educational level. ${ }^{\mathrm{d}}$ Ref.: Intermediate educational level.

${ }^{\mathrm{e}}$ Ref.: Employed full-time. ${ }^{\mathrm{f}}$ Ref.: Employed full-time. ${ }^{\mathrm{g}}$ In years. ${ }^{\mathrm{h}}$ In years. ${ }^{\mathrm{i}}$ In years

thus lend support to H1, as children's social well-being decreases when inter-parental conflict increases.

In the Models $3 \mathrm{~b}$ and $4 \mathrm{~b}$, I added the first potential mediator variables, maternal and paternal warmth, to the regression model. Maternal warmth was significantly related to both child outcomes, showing a positive association with children's prosocial behavior and a negative association with peer problems, which indicates an increase in prosocial behavior and a decrease in peer problems in children who report a perceived increase in both maternal warmth $(b=0.102, p<0.001)$ and paternal warmth $(b=0.065, p<0.001)$. Adding maternal and paternal warmth to 


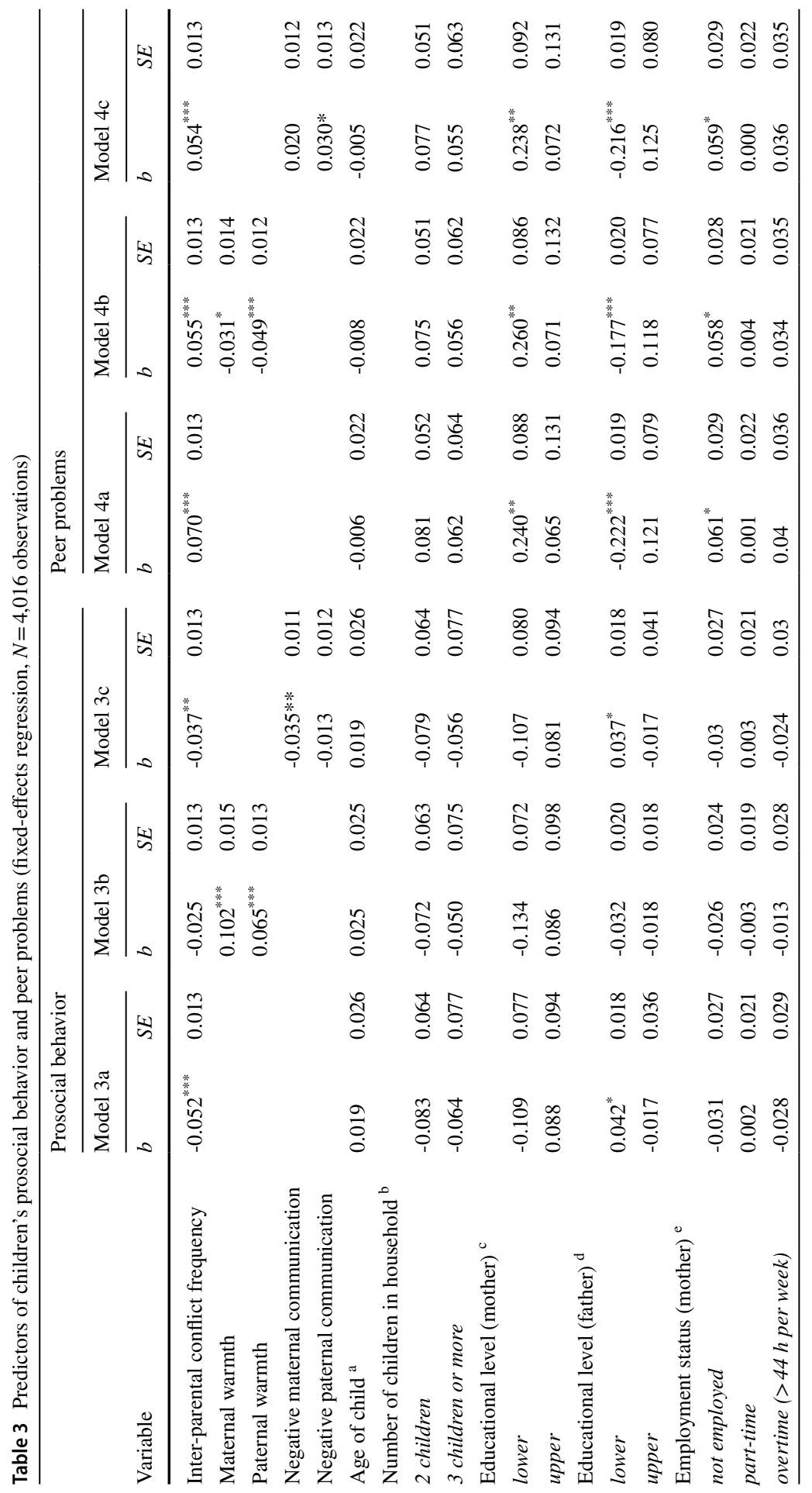




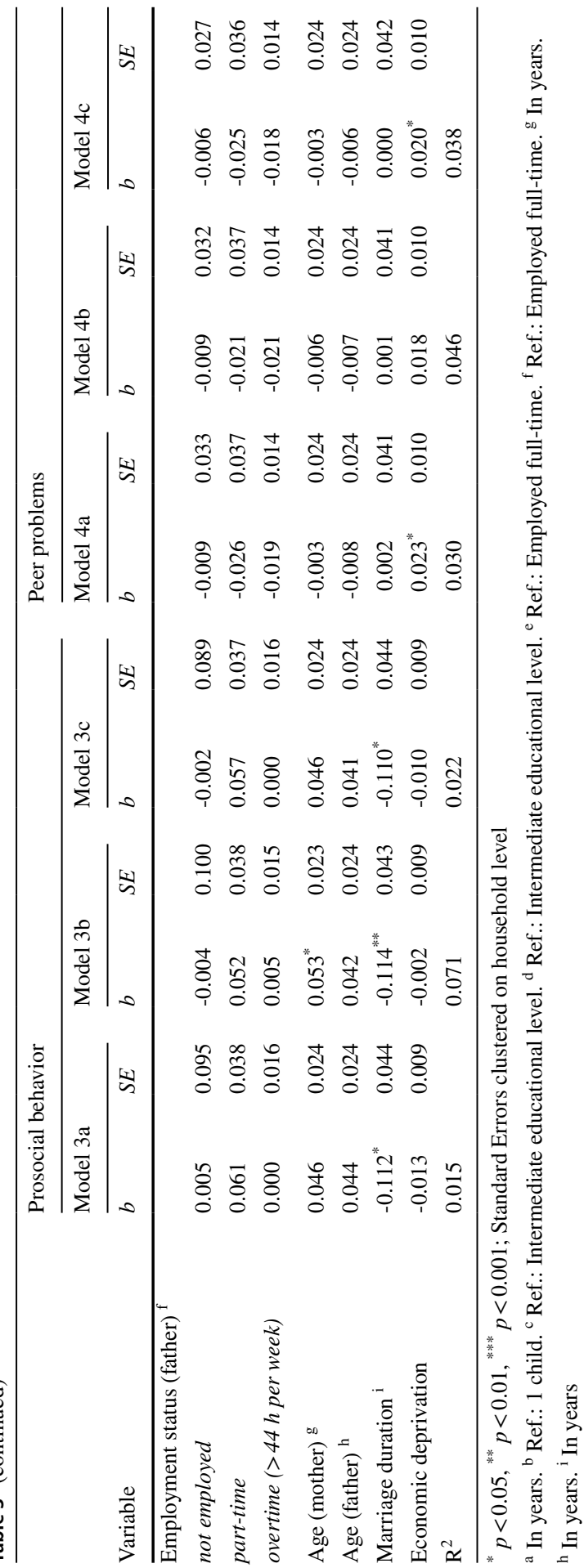


the models altered the association between inter-parental conflict frequency and children's prosocial behavior markedly: the effect of increasing inter-parental conflict frequency on children's prosocial behavior became statistically insignificant $(b=-0.025, p>0.05)$, indicating full mediation. When maternal warmth $(b=-0.031$, $p<0.05)$ and paternal warmth $(b=-0.049, p<0.001)$ were included in Model $4 \mathrm{~b}$ for changes in children's peer problems, the coefficient of increased inter-parental conflict frequency decreased substantially in size, but remained statistically significant, thus indicating partial mediation.

To evaluate whether the effect of inter-parental conflict frequency on children's social well-being was mediated by child-reported negative maternal and paternal communication, I estimated a third set of models following the same strategy (Models $3 c$ and $4 c$ in Table 3 ), adding negative maternal and paternal communication instead of maternal and paternal warmth. Changes in negative maternal communication were statistically significant predictors of changes in children's prosocial behavior $(b=-0.035, p<0.01)$, but not for changes in children's peer problems. Negative paternal communication, on the other hand, was not associated with changes in children's prosocial behavior, but was positively related to changes in children's peer problems $(b=0.030, p<0.05)$.

When controlling for negative maternal and negative paternal communication, the regression coefficients for changes in inter-parental conflict frequency decreased substantially. The association between increased inter-parental conflict frequency and changes in prosocial behavior decreased from $b=-0.052(p<0.001)$ to $b=-0.037(p<0.05)$, and the coefficient for changes in children's peer problems decreased from $b=0.070(p<0.001)$ to $b=0.054(p<0.001)$. As the relationship between increasing inter-parental conflict frequency and children's social well-being remains statistically significant in Model 3c and Model 4c, however, a partial mediation effect is indicated.

\section{Mediation Analyses}

In the last step, I quantified the indirect effects of the mediation processes (Table 4) as described in the analytical strategy. The results indicated significant indirect effects of the frequency of inter-parental conflict on children's prosocial behavior and children's peer problems through increases in maternal and paternal warmth. The indirect effect of inter-parental conflict frequency on children's prosocial behavior that is transmitted via maternal warmth was $b=-0.013(p<0.05)$, and the indirect effect transmitted via paternal warmth was $b=-0.016(p<0.05)$, which yielded a total indirect effect transmitted via parental warmth of $b=-0.029(p<0.05)$. This indicates a very strong mediating effect: $54.9 \%$ of the total effect was mediated by parental warmth. The indirect effect on peer problems via maternal warmth was $b=0.004(p<0.05)$ and $b=0.013(p<0.05)$ for paternal warmth (total indirect effect: $b=0.018 ; p<0.05$ ), which implies a mediation of $25.1 \%$ on the total effect. The significant indirect effect of negative maternal communication, on children's prosocial behavior was $b=-0.013(p<0.05)$. Negative paternal communication did not have a significant indirect effect. Finally, the significant indirect effect of 
Table 4 Indirect effects predicting the effect of inter-parental conflict through parenting behavior on children's social well-being $(N=4,016$ observations $)$

\begin{tabular}{|c|c|c|c|c|c|c|}
\hline \multirow[t]{2}{*}{ Variable } & \multicolumn{3}{|c|}{ Prosocial behavior } & \multicolumn{3}{|l|}{ Peer problems } \\
\hline & Indirect Effect & LL & UL & Indirect Effect & LL & UL \\
\hline Maternal warmth & -0.013 & -0.019 & -0.007 & 0.004 & 0.001 & 0.008 \\
\hline Paternal warmth & -0.016 & -0.023 & -0.010 & 0.013 & 0.007 & 0.020 \\
\hline Negative maternal communication & -0.013 & -0.020 & -0.006 & 0.008 & 0.001 & 0.016 \\
\hline Negative paternal communication & -0.006 & -0.013 & 0.001 & 0.012 & 0.004 & 0.021 \\
\hline
\end{tabular}

Unstandardized results of fixed effects regressions. Indirect effects were tested by using the Monte Carlo Method for Assessing Mediation (95\% confidence intervals, 500,000 repetitions, LL=lower limit; $\mathrm{UL}=$ upper limit). Significant indirect effects are highlighted in bold characters

Further controlled for the covariates age of child, number of children in the household, educational level of mother and father, occupation status of mother and father, age of mother and father, marriage duration and economic deprivation

inter-parental conflict frequency on children's peer problems transmitted via negative maternal communication was $b=0.008(p<0.05)$, and $b=0.012(p<0.05)$ for negative paternal communication. The total indirect effect mediated via negative parental communication was thus $b=0.021$, indicating that the total mediated effect is $29.5 \%$. Overall, these findings show that parental warmth is a much stronger mediator than negative communication in the effect of increasing inter-parental conflict frequency on changes in children's social well-being. Finally, the mediation analyses provided support for H4: Maternal and paternal parenting behavior does indeed mediate the effect of increasing inter-parental conflict on children's social well-being: increasing inter-parental conflict frequency is associated with a childperceived worsening of maternal and paternal parenting behavior which ultimately leads to substantially decreased social well-being in children.

\section{Additional Analyses}

In order to deepen the understanding of the mechanism and determining the role of children's gender, I analyzed the association between inter-parental conflict, the parenting behavior of mothers and fathers, and children's social well-being with regard to gender (results not reported). I estimated the sets of models according to the analytical strategy for boys (2,093 observations) and girls (1,923 observations) separately because fixed effects regressions omit variables that remain constant over time. Changes in inter-parental conflict frequency predicted changes in the warmth and negative communication of mothers and fathers for both groups. Changes in maternal and paternal warmth were also significantly associated with changes in the prosocial behavior of both boys and girls. Slight differences emerged for changes in peer problems: while the negative association between changes in maternal and paternal warmth persisted, paternal warmth but not maternal warmth was significantly associated with peer problems in boys. Another difference emerged for changes in negative communication by parents: while changes in negative paternal 
communication were not significantly related to changes in the prosocial behavior of either girls or boys, negative maternal communication was only related to changes in the prosocial behavior of boys, not girls. The analyses also revealed the significant effects of changes in negative paternal communication on changes in girls' peer problems but not boys, and changes in negative maternal communication were associated with changes in peer problems for boys but not girls.

A similar pattern for girls and boys emerged regarding the mediating effects of parenting behavior by mothers and fathers: in line with the analyses for the whole sample, maternal and paternal warmth fully mediated the effect of increases in interparental conflict frequency on the prosocial behavior of girls and boys while changes in negative communications from mothers and fathers fully mediated the effect on changes in boys' prosocial behavior, and partially for girls. Negative parental communication partially mediated the effect of increases in the frequency of inter-parental conflict on changes in the peer problems of boys and girls.

Lastly, I examined the age and developmental state of children more closely in additional analyses. Neither changes in the metric age nor changes in developmental state - child (age 7 to 10) versus early adolescence (age 11 to 13) and mid- to late adolescence (age 14 to 16) - were significant in any of the models. The mechanism thus seems to stay the same for children and adolescents, independent of their age.

\section{Discussion}

In today's society, prosocial behavior and adequate peer behavior are important for flourishing as they promote success in private and work life and are associated with a higher quality of life for children and adolescents (Dou et al., 2019; Lavy, 2020; Shek \& Chai, 2020; Zhou et al., 2021), which reinforces the need to understand the mechanisms that lead to those behaviors. Previous studies have documented the harmful effect of inter-parental conflict on children's social well-being (e.g., Gong \& Paulson, 2017; Holmes et al., 2015; McCoy et al., 2009). Using data from the German Family Panel, pairfam, this study intended to broaden our understanding of the intersection between inter-parental conflict and children's social well-being by applying panel regression analyses and mediation modeling to test three empirical relationships: (1) the association between an increasing frequency of inter-parental conflict and changes in children's social well-being, (2) the association between the frequency of inter-parental conflict and changes in parenting behavior by mothers and fathers, and (3) the mediating effect of maternal and paternal parenting behavior on the relationship between changes in the frequency of inter-parental conflict and children's social well-being.

Overall, the results are well in line with past findings from US American studies (e.g., Holmes et al., 2015; McCoy et al., 2013). Despite the differences in parenting behavior, the time budgets of families, and family values in Germany and the USA (Doepke \& Zilibotti, 2019; Halman et al., 2007; OECD, 2014, 2016, 2020), I find that children who are exposed to more frequent conflict between parents seem to be prone to transfer the commonly observed behaviors in their parents to the school environment, and have more peer problems and behave in a less prosocial manner. 
This provides further empirical evidence for social learning theory (Bandura, 1969; Bandura \& Walters, 1977).

This study explored the effect of changes in the frequency of inter-parental conflict on children's social well-being rather than levels of inter-parental conflict, in order to deepen our understanding of this association and acknowledge that the frequency of conflict is unlikely to be constant over time. An increased frequency of inter-parental conflict repeatedly exposes children to situations of social conflict within the family environment, which might elicit changes in children's social behavior and well-being (e.g., Miller et al., 2010; Power, 2004) because the children of parents who argue more frequently witness conflict and the associated adverse social behaviors more often, and may therefore accept these behaviors as normal (McCord, 1988), thus imitating their parents' (conflict) behavior (Bandura \& Walters, 1977; Halberstadt et al., 1993). The empirical evidence provided in this study hints at a spillover process from home to the school environment in children, and suggests that it is not only the overall level of inter-parental conflict that contributes to a deterioration in children's social well-being, but also that an increasing frequency of inter-parental conflict has severe negative effects on children's social well-being as well.

The analyses also shed light on the underlying mechanism of the association between increases in inter-parental conflict frequency and changes in children's prosocial behavior and peer problems. While previous studies showed that parenting behavior and parenting stress have a mediating effect on the association between parental conflict and internalizing and externalizing problems in children (e.g., Camisasca et al., 2016; Coln et al., 2013), the present study complements and expands our knowledge by focusing more narrowly on the emotional warmth and negative communication of mothers and fathers. The analyses indicated that maternal and paternal parenting behavior is highly responsive to inter-parental conflict frequency: an increase in inter-parental conflict frequency is accompanied by a decrease in the warmth of both parents and an increase in negative communication between parents and their children. It is noteworthy that I did find some evidence for the father vulnerability hypothesis, which suggests that fathers react with more vulnerability to inter-parental conflict than mothers, and alter their parenting behavior more strongly when there is conflict within the family environment (Cummings et al., 2004, 2010; Goeke-Morey \& Mark Cummings, 2007; Krishnakumar \& Buehler, 2000). Indeed, the analyses revealed that changes in inter-parental conflict have a much greater effect on a father's warmth and a slightly greater effect on negative communication compared to maternal parenting.

The mediation analyses identified parental warmth in particular as a powerful mediator when considering the effect of the frequency of inter-parental conflict on changes in children's social well-being. As perceived by the children, mothers and fathers seem to be less likely to express affection or cheer their children up when they are sad or upset, and more likely to berate, quarrel with, and criticize their children in the children's perceptions. These changes in parenting behavior, in turn, are associated with decreased social well-being in children: more peer problems and less prosocial behavior. These findings are well in line with the arguments of emotional security theory (EST), which proposes a cascade that transmits the effects of 
inter-parental conflict to children's well-being (Davies \& Cummings, 1994), and with the spillover hypothesis, as well as empirical evidence provided by earlier studies (e.g., Holmes et al., 2015; Hosokawa \& Katsura, 2017; McCoy et al., 2009, 2013; Miga et al., 2012). However, I did not find evidence in favor of the compensatory hypothesis (Engfer, 1988): both parents act less warmly and communicate more negatively with the child, which ultimately leads to lower social well-being. The analyses further revealed that the warmth of parents has stronger mediating effects than negative communication. Changes in the emotional component within the family system seem to have a greater effect on changes in children's social well-being than changes in the communicative component. Interestingly, maternal parenting behavior has a stronger negative effect on changes in children's prosocial behavior while a father's parenting behavior is more strongly associated with increasing peer problems.

Finally, although some studies have examined the association between interparental conflict and children's social behavior and social well-being (e.g., Holmes et al., 2015; McCoy et al., 2009, 2013; Troxel \& Matthews, 2004), the child's perspective has received less attention. By incorporating children's reports of interparental conflict and their self-reports of social well-being, the current study aimed to reduce possible biases compared to earlier analyses that only used reports from parents and teachers reports (e.g., Brock \& Kochanska, 2016; Gryczkowski et al., 2018; Harold et al., 2007). In light of the existing empirical evidence that children perceive their well-being and family environments very differently from their parents and teachers, and that adults' reports are not always congruent with children's (e.g., Seiffge-Krenke \& Kollmar, 1998; White-Koning et al., 2007), it is essential to consider children's self-reports when seeking to explain the effect of the frequency of inter-parental conflict on children's social well-being. However, the empirical evidence also suggests that the detrimental effects of inter-parental conflict are persistent when using child- and adolescent-reported measures, confirming the parentand teacher-reports.

\section{Limitations}

While the present study advances the current body of literature by testing changes in inter-parental conflict frequency with longitudinal, child-reported data, and providing evidence of how parenting behavior functions as a mediator between interparental conflict and child outcomes, some limitations should be addressed.

First, I only tested the effect of increases in inter-parental conflict frequency in this study. It would be valuable to test whether declining inter-parental conflict leads to an increase in children's social well-being, and also to examine the effects of constant high levels of inter-parental conflict. This study also concentrated on conflict frequency only. Some studies have shown that, in addition to conflict frequency, parental conflict resolution behavior and hostility between parents contribute to children's emotional and behavioral problems (for an overview see van Eldik et al., 2020). It would thus be beneficial to utilize more complex conflict measures to determine coping strategies for within-family conflicts more 
effectively. Secondly, this study employed the child's perspective only. A multiinformant approach that incorporates the parents' assessment of parenting behavior would be beneficial to improve the reliability of the findings by cross-validating the parents' behaviors (e.g., Camisasca et al., 2016; Harold et al., 2007). Third, I need to address the limitations of fixed-effects regressions: FE models suffer from a number of limitations ranging from culture of omission (e.g., timefixed traits like gender), limited external validity and low statistical power (Hill et al., 2020). Indeed, the effect sizes in this study are relatively small, which is not unusual for psychological and social scientific studies (Bosco et al., 2015; Cohen, 2013) The results of this study should therefore be interpreted with care. Fourth, the causal direction assumed in this study is not undisputed. Although it is reasonably and generally assumed that inter-parental conflict determines the social well-being of parents and children, there is some empirical evidence that child problems might be bi-directionally associated with inter-parental conflict, coparenting conflict, and parenting practices (e.g., Choi et al., 2019; Howard et al., 2019; Larsson et al., 2008; Salari et al., 2014; Zvara et al., 2018). Lastly, the research on child and adolescent outcomes may suffer from poor external validity: most of the studies conducted on the effect of inter-parental conflict on child and adolescent outcomes stem from Western researchers and rely on data from Western countries; it is not conclusively clear whether the results can be transferred without restriction to other cultural contexts (Nielsen et al., 2017; Qi et al., 2020). This study is no exception to this Western bias. Future research should urgently address this research gap.

Notwithstanding the aforementioned limitations, this study overall provides empirical evidence for the negative impact of inter-parental conflict on children's social well-being through a cascade of negative behavior within the family environment that spills over to the school environment. Children of parents who have frequent inter-parental conflicts perceive their mothers and fathers to be less warm and to communicate more negatively, which, in turn, leads to more peer problems and less prosocial behavior in those children.

Acknowledgements I am grateful to Jan Delhey, Matthias Pollmann-Schult and Christian Schneickert for their comments and support. I would also like to thank the two anonymous reviewers for their valuable comments and suggestions.

Funding Open Access funding enabled and organized by Projekt DEAL.

Availability of data and material This paper uses data from the German Family Panel pairfam, coordinated by Josef Brüderl, Sonja Drobnič, Karsten Hank, Franz J. Neyer, and Sabine Walper. pairfam is funded as long-term project by the German Research Foundation (DFG).

pairfam data is available as scientific use file (Brüderl, J., Drobnič, S., Hank, K., Neyer, F. K., Walper, S., Alt, P., Borschel, E., Bozoyan, C., Garrett, M., Geissler, S., Gonzalez Avilés, T., Gröpler, N., Hajek, K., Herzig, M., Huyer-May, B., Lenke, R., Lorenz, R., Lutz, K., Minkus, L., Peter, T., Phan, T., Preetz, R., Reim, J., Sawatzki, B., Schmiedeberg, C., Schütze, P., Schumann, N., Thönnissen, C., Timmermann K. \& Wetzel, M. (2021). The German Family Panel (pairfam). GESIS Data Archive, Cologne. ZA5678 Data file Version 12.0.0, https://doi.org/10.4232/pairfam.5678.12.0.0).

Code availability Stata Code is available on request, custom code. 


\section{Declarations}

Conflicts of interest The author declares that she has no conflict of interest.

Open Access This article is licensed under a Creative Commons Attribution 4.0 International License, which permits use, sharing, adaptation, distribution and reproduction in any medium or format, as long as you give appropriate credit to the original author(s) and the source, provide a link to the Creative Commons licence, and indicate if changes were made. The images or other third party material in this article are included in the article's Creative Commons licence, unless indicated otherwise in a credit line to the material. If material is not included in the article's Creative Commons licence and your intended use is not permitted by statutory regulation or exceeds the permitted use, you will need to obtain permission directly from the copyright holder. To view a copy of this licence, visit http://creativecommons.org/licen ses/by/4.0/.

\section{References}

Allison, P.D. (2009). Fixed effects regression models (Vol. 160). SAGE publications.

Auersperg, F., Vlasak, T., Ponocny, I., \& Barth, A. (2019). Long-term effects of parental divorce on mental health - A meta-analysis. Journal of Psychiatric Research, 119, 107-115. https://doi.org/10. 1016/j.jpsychires.2019.09.011

Autorengruppe Bildungsberichterstattung. (2020). Bildung in Deutschland 2020. Ein indikatorengestützer Bericht mit einer Analyse zu Bildung in einer digitalisierten Welt. https://www.bildungsbericht.de/ static_pdfs/bildungsbericht-2020.pdf. Accessed 01.112020.

Bandura, A. (1969). Social-learning theory of identificatory processes. Handbook of Socialization Theory and Research, 213, 262.

Bandura, A., \& Walters, R.H. (1977). Social learning theory (Vol. 1). Prentice Hall.

Bosco, F. A., Aguinis, H., Singh, K., Field, J. G., \& Pierce, C. A. (2015). Correlational effect size benchmarks. Journal of Applied Psychology, 100(2), 431.

Boyce, C. J. (2010). Understanding fixed effects in human well-being. Journal of Economic Psychology, 31(1), 1-16.

Brock, R. L., \& Kochanska, G. (2016). Interparental conflict, children's security with parents, and longterm risk of internalizing problems: A longitudinal study from ages 2 to 10. Development and Psychopathology, 28(1), 45-54. https://doi.org/10.1017/S0954579415000279

Brüderl, J., Schmiedeberg, C., Castiglioni, L., Becker, O.A., Buhr, P., Fuß, D., Ludwig, V., Schröder, J., \& Schumann, N. (2017). pairfam Technical Paper. https://www.pairfam.de/fileadmin/user_upload/ redakteur/publis/Dokumentation/TechnicalPapers/TP01\%20Cumulated\%20Field\%20Report $\% 2$ C\% 20pairfam\%202021.pdf. Accessed 08.12. 2020.

Brummert Lennings, H. I., \& Bussey, K. (2017). The mediating role of coping self-efficacy beliefs on the relationship between parental conflict and child psychological adjustment. Social Development, 26(4), 753-766. https://doi.org/10.1111/sode.12241

Camisasca, E., Miragoli, S., \& Di Blasio, P. (2016). Families with distinct levels of marital conflict and child adjustment: Which role for maternal and paternal stress? Journal of Child and Family Studies, 25(3), 733-745. https://doi.org/10.1007/s10826-015-0261-0

Choi, J.-K., Parra, G., \& Jiang, Q. (2019). The longitudinal and bidirectional relationships between cooperative coparenting and child behavioral problems in low-income, unmarried families. Journal of Family Psychology, 33(2), 203-214. https://doi.org/10.1037/fam0000498

Cohen, J. (2013). Statistical power analysis for the behavioral sciences. Academic Press.

Coln, K. L., Jordan, S. S., \& Mercer, S. H. (2013). A unified model exploring parenting practices as mediators of marital conflict and children's adjustment. Child Psychiatry \& Human Development, 44(3), 419-429.

Cummings, E.M., Goeke-Morey, M.C., \& Raymond, J. (2004). Fathers in family context: effects of marital quality and marital conflict. In M. Lamb (Ed.), The role of the father in child development (4th ed., pp. 196-221). Wiley. 
Cummings, E, M,. Merrilees. C, E, \& George. M, W, (2010), Fathers, marriages, and families: Revisiting and updating the framework for fathering in family context. In M. E. Lamb (Ed.). The role of the father in child development (pp, 154-176), Wiley.

Davies, P. T., \& Cummings, E. M. (1994). Marital conflict and child adjustment: An emotional security hypothesis. Psychological Bulletin, 116(3), 387-411. https://doi.org/10.1037/0033-2909.116.3.387

Davies, P. T., Hentges, R. F., Coe, J. L., Martin, M. J., Sturge-Apple, M. L., \& Cummings, E. M. (2016). The multiple faces of interparental conflict: Implications for cascades of children's insecurity and externalizing problems. Journal of Abnormal Psychology, 125(5), 664-678. https://doi.org/10.1037/ abn0000170

Dickerson, S. W. (2021). Maternal psychological well-being and offspring's outcomes in Peru: A quantitative analysis. Applied Research in Quality of Life, 16(2), 527-571. https://doi.org/10.1007/ s11482-019-09757-6

Doepke, M., \& Zilibotti, F. (2019). Parenting Styles around the Contemporary World Love, Money, and Parenting (pp. 85-124). Princeton University Press.

Dou, K., Li, J.-B., Wang, Y.-J., Li, J.-J., Liang, Z.-Q., \& Nie, Y.-G. (2019). Engaging in prosocial behavior explains how high self-control relates to more life satisfaction: Evidence from three Chinese samples. PLoS ONE, 14(10), e0223169. https://doi.org/10.1371/journal.pone.0223169

Elemary, F., Al Omari, O., \& Wynaden, D. (2016). The perception of adolescents' inter-parental conflict and accompanied emotional security: A descriptive study. Journal of Nursing Education and Practice, 6(5), 84-90.

Engfer, A. (1988). The interrelatedness of marriage and the mother-child relationship. In R. A. Hinde \& J. Stevenson-Hinde (Eds.), Relationships within families: Mutual influences (pp. 105-118). Clarendon Press.

Erel, O., \& Burman, B. (1995). Interrelatedness of marital relations and parent-child relations: A metaanalytic review. Psychological Bulletin, 118(1), 108-132. https://doi.org/10.1037/0033-2909.118.1. 108

Firebaugh, G., Warner, C., \& Massoglia, M. (2013). Fixed effects, random effects, and hybrid models for causal analysis. In S. L. Morgan (Ed.), Handbook of Causal Analysis for Social Research (pp. 113-132). Springer.

Flouri, E., Sarmadi, Z., \& Francesconi, M. (2019). Paternal psychological distress and child problem behavior from early childhood to middle adolescence. Journal of the American Academy of Child and Adolescent Psychiatry, 58(4), 453-458. https://doi.org/10.1016/j.jaac.2018.06.041

Gödde, M., \& Walper, S. (2001). Elterliche Konflikte aus der Sicht von Kindern und Jungdlichen: Die deutsche Kurzfassung der Children's Perception of Interparental Conflict Scale (CPIC). [The German short version of the Children's Perception of Interparental Conflict Scale.]. Diagnostica, 47(1), 18-26, https://doi.org/10.1026//0012-1924.47.1.18.

Goeke-Morey, M. C., \& Mark Cummings, E. (2007). Impact of father involvement: A closer look at indirect effects models involving marriage and child adjustment. Applied Developmental Science, 11(4), 221-225. https://doi.org/10.1080/10888690701762126

Gong, X., \& Paulson, S. E. (2017). Effect of family affective environment on individuals' emotion regulation. Personality and Individual Differences, 117, 144-149. https://doi.org/10.1016/j.paid.2017.05. 047

Goodman, R. (1997). The strengths and difficulties questionnaire: A research note. The Journal of Child Psychology and Psychiatry, 38(5), 581-586. https://doi.org/10.1111/j.1469-7610.1997.tb01545.x

Grych, J. H., Seid, M., \& Fincham, F. D. (1992). Assessing marital conflict from the child's perspective: The Children's perception of interparental conflict scale. Child Development, 63(3), 558-572. https://doi.org/10.1111/j.1467-8624.1992.tb01646.x

Gryczkowski, M., Jordan, S. S., \& Mercer, S. H. (2018). Moderators of the relations between mothers' and fathers' parenting practices and children's prosocial behavior. Child Psychiatry \& Human Development, 49(3), 409-419. https://doi.org/10.1007/s10578-017-0759-3

Halberstadt, A. G., Fox, N. A., \& Jones, N. A. (1993). Do expressive mothers have expressive children? The role of socialization in children's affect expression. Social Development, 2(1), 48-65. https:// doi.org/10.1111/j.1467-9507.1993.tb00004.x

Halman, L., Inglehart, R.L., Díez-Medrano, J., Luijkx, R., Moreno, A., \& Basáñez, M. (2007). Changing values and beliefs in 85 countries: Trends from the values surveys from 1981 to 2004 . Brill.

Harold, G. T., Aitken, J. J., \& Shelton, K. H. (2007). Inter-parental conflict and children's academic attainment: A longitudinal analysis. Journal of Child Psychology and Psychiatry, 48(12), 1223-1232. 
Hayes, A. F. (2013). Introduction to mediation, moderation, and conditionalprocess analysis: A regression-based approach. The Guilford Press.

Hill, T. D., Davis, A. P., Roos, J. M., \& French, M. T. (2020). Limitations of fixed-effects models for panel data. Sociological Perspectives, 63(3), 357-369. https://doi.org/10.1177/0731121419863785

Holmes, M. R., Voith, L. A., \& Gromoske, A. N. (2015). Lasting effect of intimate partner violence exposure during preschool on aggressive behavior and prosocial skills. Journal of Interpersonal Violence, 30(10), 1651-1670. https://doi.org/10.1177/0886260514552441

Hosokawa, R., \& Katsura, T. (2017). Marital relationship, parenting practices, and social skills development in preschool children. Child and Adolescent Psychiatry and Mental Health, 11(1), 1-8. https:// doi.org/10.1186/s13034-016-0139-y

Howard, K. R., Reinecke, M. A., Lavigne, J. V., Gouze, K. R., \& Jordan, N. (2019). Marital and parent-child relationships during treatment for adolescent depression: Child-driven and bidirectional effects. Journal of Abnormal Child Psychology, 47(11), 1841-1850. https://doi.org/10.1007/ s10802-019-00566-X

Huinink, J., Brüderl, J., Nauck, B., Walper, S., Castiglioni, L., \& Feldhaus, M. (2011). Panel analysis of intimate relationships and family dynamics (pairfam): Conceptual framework and design. Zeitschrift Für Familienforschung/journal of Family Research, 23(1), 77-101.

Jaursch, S. (2003). Erinnertes und aktuelles Erziehungsverhalten von Müttern und Vätern: intergenarationale Zusammenhänge und kontextuelle Faktoren: Inaugural Dissertation: Friedrich-Alexander-Universität.

Katrijn, M. B., Soenens, B., Van Petegem, S., \& Kins, E. (2017). Searching for the roots of overprotective parenting in emerging adulthood: Investigating the link with parental attachment representations using an Actor Partner Interdependence Model (APIM). Journal of Child and Family Studies, 26(8), 2299-2310.

Keller, M., \& Kahle, I. (2018). Realisierte Erwerbstätigkeit von Müttern und Vätern zur Vereinbarkeit von Familie und Beruf. https://www.destatis.de/DE/Methoden/WISTA-Wirtschaft-und-Statistik/ 2018/03/realisierte-erwerbstaetigkeit-032018.pdf?_blob=publicationFile. Accessed 09.12. 2020.

Klasen, H., Woerner, W., Wolke, D., Meyer, R., Overmeyer, S., Kaschnitz, W., Rothenberger, A., \& Goodman, R. (2000). Comparing the German versions of the Strengths and Difficulties Questionnaire (SDQ-Deu) and the Child Behavior Checklist. European Child \& Adolescent Psychiatry, 9(4), 271-276. https://doi.org/10.1007/s007870070030

Koçak, A., Mouratidis, A., Sayıl, M., Kındap-Tepe, Y., \& Uçanok, Z. (2017). Interparental conflict and adolescents' relational aggression and loneliness: The mediating role of maternal psychological control. Journal of Child and Family Studies, 26(12), 3546-3558. https://doi.org/10.1007/ s10826-017-0854-X

Koskelainen, M., Sourander, A., \& Kaljonen, A. (2000). The Strengths and Difficulties Questionnaire among Finnish school-aged children and adolescents. European Child \& Adolescent Psychiatry, 9(4), 277-284. https://doi.org/10.1007/s007870070031

Kouros, C. D., Cummings, E. M., \& Davies, P. T. (2010). Early trajectories of interparental conflict and externalizing problems as predictors of social competence in preadolescence. Development and Psychopathology, 22(3), 527-537. https://doi.org/10.1017/S0954579410000258

Kouros, C. D., Papp, L. M., Goeke-Morey, M. C., \& Cummings, E. M. (2014). Spillover between marital quality and parent-child relationship quality: Parental depressive symptoms as moderators. Journal of Family Psychology, $28(3), 315$.

Krishnakumar, A., \& Buehler, C. (2000). Interparental conflict and parenting Behaviors: A meta-analytic review. Family Relations, 49(1), 25-44. https://doi.org/10.1111/j.1741-3729.2000.00025.x

Larsson, H., Viding, E., Rijsdijk, F. V., \& Plomin, R. (2008). Relationships between parental negativity and childhood antisocial behavior over time: A bidirectional effects model in a longitudinal genetically informative design. Journal of Abnormal Child Psychology, 36(5), 633-645. https:// doi.org/10.1007/s10802-007-9151-2

Lavy, S. (2020). A review of character strengths interventions in twenty-first-century schools: Their importance and how they can be fostered. Applied Research in Quality of Life, 15(2), 573-596. https://doi.org/10.1007/s11482-018-9700-6

Li, C. (2013). Little's test of missing completely at random. The Stata Journal, 13(4), 795-809.

Low, Y. T. A. (2021). Family conflicts, anxiety and depressive symptoms, and suicidal ideation of Chinese adolescents in Hong Kong. Applied Research in Quality of Life, 1-18,. https://doi.org/ $10.1007 / \mathrm{s} 11482-021-09925-7$ 
McCord, J. (1988). Parental behavior in the cycle of aggression. Psychiatry, 51(1), 14-23. https://doi. org/10.1080/00332747.1988.11024376

McCoy, K. P., Cummings, E. M., \& Davies, P. T. (2009). Constructive and destructive marital conflict, emotional security and children's prosocial behavior. Journal of Child Psychology and Psychiatry, 50(3), 270-279. https://doi.org/10.1111/j.1469-7610.2008.01945.x

McCoy, K. P., George, M. R., Cummings, E. M., \& Davies, P. T. (2013). Constructive and destructive marital conflict, parenting, and children's school and social adjustment. Social Development, 22(4), 641-662. https://doi.org/10.1111/sode.12015

Miga, E. M., Gdula, J. A., \& Allen, J. P. (2012). Fighting fair: Adaptive marital conflict strategies as predictors of future adolescent peer and romantic relationship quality. Social Development, 21(3), 443-460. https://doi.org/10.1111/j.1467-9507.2011.00636.x

Miller, P. A., Kliewer, W., \& Partch, J. (2010). Socialization of children's recall and use of strategies for coping with interparental conflict. Journal of Child and Family Studies, 19(4), 429-443. https://doi.org/10.1007/s10826-009-9314-6

Nielsen, M., Haun, D., Kärtner, J., \& Legare, C. H. (2017). The persistent sampling bias in developmental psychology: A call to action. Journal of Experimental Child Psychology, 162, 31-38. https://doi. org/10.1016/j.jecp.2017.04.017

Nikolaou, D. (2017). Maternal life satisfaction, marital status, and child skill formation. Eastern Economic Journal, 43(4), 621-648. https://doi.org/10.1057/eej.2015.48

O'Hara, K. L., Sandler, I. N., Wolchik, S. A., \& Tein, J.-Y. (2019). Coping in context: The effects of longterm relations between interparental conflict and coping on the development of child psychopathology following parental divorce. Development and Psychopathology, 31(5), 1695-1713. https://doi. org/10.1017/S0954579419000981

Organisation for Economic Co-operation and Development (OECD). (2014). Average annual hours actually worked. https://www.oecd-ilibrary.org/content/data/data-00303-en. Accessed 08.12. 2020.

Organisation for Economic Co-operation and Development (OECD). (2016). How is learning time organised in primary and secondary education? Education Indicators in Focus, 38, 1-4. https://doi.org/ $10.1787 / 22267077$

Organisation for Economic Co-operation and Development (OECD). (2020). Education at a glance 2020. OECD Publishing. https://doi.org/10.1787/69096873-en

Power, T.G. (2004). Stress and coping in childhood: The parents' role. Parenting: Science and Practice, 4(4), 271-317, https://doi.org/10.1207/s15327922par0404_1.

Preacher, K. J., \& Hayes, A. F. (2008). Asymptotic and resampling strategies for assessing and comparing indirect effects in multiple mediator models. Behavior Research Methods, 40(3), 879-891. https:// doi.org/10.3758/brm.40.3.879

Preacher, K. J., \& Selig, J. P. (2012). Advantages of Monte Carlo confidence intervals for indirect effects. Communication Methods and Measures, 6(2), 77-98. https://doi.org/10.1080/19312458.2012. 679848

Qi, S., Hua, F., Zhou, Z., \& Shek, D. T. L. (2020). Trends of positive youth development publications (1995-2020): A scientometric review. Applied Research in Quality of Life, 1-26,. https://doi.org/10. 1007/s11482-020-09878-3

Salari, R., Wells, M. B., \& Sarkadi, A. (2014). Child behaviour problems, parenting behaviours and parental adjustment in mothers and fathers in Sweden. Scandinavian Journal of Public Health, 42(7), 547-553. https://doi.org/10.1177/1403494814541595

Schwarz, B., Walper, S., Gödde, M., \& Jurasic, S. (1997). Dokumentation der Erhebungsinstrumente der 1. Haupterhebung (überarbeitete Version). Berichte aus der Arbeitsgruppe Familienentwicklung nach der Trennung, 14, 1997.

Seiffge-Krenke, I., \& Kollmar, F. (1998). Discrepancies between mothers' and fathers' perceptions of sons' and daughters' problem behaviour: A longitudinal analysis of parent-adolescent agreement on internalising and externalising problem behaviour. Journal of Child Psychology and Psychiatry and Allied Disciplines, 39(5), 687-697. https://doi.org/10.1111/1469-7610.00368

Selig, J.P., \& Preacher, K.J. (2008). Monte Carlo method for assessing mediation: An interactive tool for creating confidence intervals for indirect effects [Computer software]. http://quantpsy.org/. Accessed 08.12. 2020.

Shek, D. T. L., \& Chai, W. (2020). The impact of positive youth development attributes and life satisfaction on academic well-being: A longitudinal mediation study. Frontiers in Psychology, 11, 21262126. https://doi.org/10.3389/fpsyg.2020.02126 
Troxel, W. M., \& Matthews, K. A. (2004). What are the costs of marital conflict and dissolution to children's physical health? Clinical Child and Family Psychology Review, 7(1), 29-57. 10.1023/b:ccfp. $0000020191.73542 . b 0$

van Eldik, W. M., de Haan, A. D., Parry, L. Q., Davies, P. T., Luijk, M. P., Arends, L. R., \& Prinzie, P. (2020). The interparental relationship: Meta-analytic associations with children's maladjustment and responses to interparental conflict. Psychological Bulletin, 146(7), 553-594. https://doi.org/10. 1037/bul0000233

Vandewater, E. A., \& Lansford, J. E. (1998). Influences of family structure and parental conflict on children's well-being. Family Relations, 47(4), 323-330. https://doi.org/10.2307/585263

Waters, E., Stewart-Brown, S., \& Fitzpatrick, R. (2003). Agreement between adolescent self-report and parent reports of health and well-being: results of an epidemiological study. Child: Care, Health and Development, 29(6), 501-509, https://doi.org/10.1046/j.1365-2214.2003.00370.x.

White-Koning, M., Arnaud, C., Dickinson, H. O., Thyen, U., Beckung, E., Fauconnier, J., McManus, V., Michelsen, S. I., Parkes, J., Parkinson, K., Schirripa, G., \& Colver, A. (2007). Determinants of child-parent agreement in quality-of-life reports: A European study of children with cerebral palsy. Pediatrics, 120(4), e804-814. https://doi.org/10.1542/peds.2006-3272

Youth in Mind. (2012). Information for researchers and professionals about the Strengths \& Difficulties Questionnaires. https://www.sdqinfo.org/. Accessed 08.12. 2020.

Zemp, M., Johnson, M. D., \& Bodenmann, G. (2018). Within-family processes: Interparental and coparenting conflict and child adjustment. Journal of Family Psychology, 32(3), 299-309. https://doi.org/ 10.1037/fam0000368

Zemp, M., Merrilees, C. E., \& Bodenmann, G. (2014). How much positivity is needed to buffer the impact of parental negativity on children? Family Relations, 63(5), 602-615. https://doi.org/10. 1111/fare.12091

Zhou, Z., Shek, D. T. L., Zhu, X., \& Lin, L. (2021). The influence of moral character attributes on adolescent life satisfaction: The mediating role of responsible behavior. Child Indicators Research, 14(3), 1293-1313. https://doi.org/10.1007/s12187-020-09797-7

Zvara, B. J., Sheppard, K. W., \& Cox, M. (2018). Bidirectional effects between parenting sensitivity and child behavior: A cross-lagged analysis across middle childhood and adolescence. Journal of Family Psychology, 32(4), 484-495. https://doi.org/10.1037/fam0000372

Publisher's Note Springer Nature remains neutral with regard to jurisdictional claims in published maps and institutional affiliations. 